\title{
Modelling sustainable urban travel in a whole systems energy model
}

\author{
Steve Pye ${ }^{1}$ and Hannah Daly
}

UCL Energy Institute, University College London

14 Upper Woburn Place, London, WC1H 0NN, United Kingdom

Tel: +44 (0)2031085989

${ }^{1}$ Corresponding author, e-mail: s.pye@ucl.ac.uk

\begin{abstract}
Many proposed low carbon transitions of the transport system have focused on decarbonisation in terms of technological transformation; however, significant opportunities exist for behavioural or demand side orientated measures to play an important role. This paper explores how one such option, mode shift, can contribute to low-carbon energy systems. For the first time, endogenous mode choice is integrated into a whole energy systems model, ESME, by representing mode speed, travel time budgets, infrastructure costs, and maximum rates of modal shift. Results indicate that the cost-optimal model solution favours sustainable transport modes, although this is strongly contingent on financial disincentives for car travel and measures to make slower modes more attractive. This approach is relevant in many different country contexts, as the need to assess options for lower carbon, more sustainable urban transport systems increases.
\end{abstract}

\section{Highlights}

* Developed approach for endogenising modal shift in energy systems model

* Explored role of mode shift options in UK low carbon scenarios

* Identified important role for option in meeting urban passenger transport demand

Keywords: energy system models, modal shift

\section{Introduction}

The transport sector plays a critical role in enabling economic growth and facilitating consumer choices around, for example, employment opportunities, where to live and how to spend leisure time. In the UK, demand for passenger transport has increased four-fold in the last 60 years, and has largely been driven by an increase in car ownership and use (Figure 1). Combined with freight transport, this growth in demand means that the transport sector is a key source of $\mathrm{CO}_{2}$ emissions, accounting for $20 \%{ }^{1}$

\footnotetext{
${ }^{1}$ UK Greenhouse Gas Inventory, 1990 to 2012. Annual Report for Submission under the Framework Convention on Climate Change. April 2014. https://www.gov.uk/government/publications/uk-greenhouse-gas-inventory
} 
Tackling emissions in the transport sector is therefore imperative if the UK is to achieve its domestic emission reduction goals.

Many of the analyses of low carbon transitions have considered how the transport system could decarbonise in terms of technological transformation [1] [2], with so-called E3 models ${ }^{2}$ typically used in such studies. Schäfer [3] provides an overview of the types of demand side and behavioural measures that are incorporated into different E3-type models for the transport sector, and highlights their limited representation in bottom-up type optimisation models, whose focus is on technology and fuel deployment. The noted exception is price-induced demand response, which is typically incorporated in MARKAL/TIMES models, and in ESME [4].

Figure 1. Terrestrial passenger transport demand by mode in the UK, 1952 - 2012

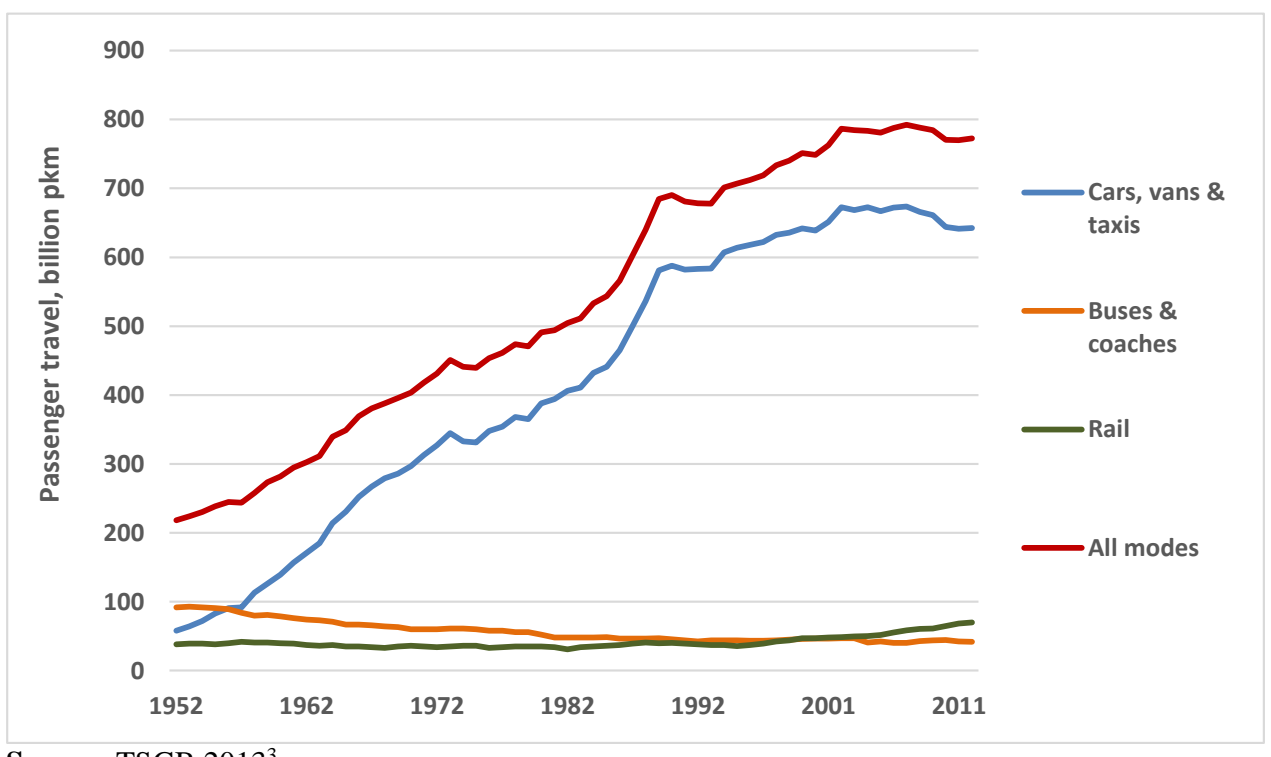

Source: TSGB $2013^{3}$

While the large-scale uptake of low carbon technologies is critical, significant opportunities exist for demand side orientated measures to play an important role [5] [6] [7]. This includes reducing travel intensity, reducing demand through price mechanisms, and increasing non-car transport alternatives. Reducing travel intensity by increasing the number of passengers supplied for every vehicle-km travelled can be done through introducing high-occupancy vehicle lanes, workplace measures to encourage vehicle sharing and the use of digital ride sharing, enabled by the internet. Financial

\footnotetext{
${ }^{2}$ E3 means energy system models that incorporate the following systems elements partially or comprehensively - energy, economy, and environment.

${ }^{3}$ Transport Statistics Great Britain 2013, https://www.gov.uk/government/statistics/transport-statistics-great-britain-2013
} 
mechanisms, including use-based pricing, can also be effective demand side measures; congestion charging for example has been shown to reduced travel delay, improved journey time reliability, lower fuel consumption, and reduce pollution and accidents [8] [9].

In the UK, the potential of such measures has been quantified. Gross et al. [10] highlight the significant potential for carbon emission reductions from changing behaviour patterns in personal transportation through persuading people to reduce number of trips, switch modes and use cars more efficiently. Measures include increased uptake of non-motorised modes (6\% emission reduction relative to current road transport levels if comparable Northern European levels were reached), increased use of public transport, eco-driving (10-15\% car emission reduction), use of smarter measures e.g. travel planning (5-10\% car emission reductions) and road user charges.

Cairns et al. [11] assess the role of smarter choices, 'soft' initiatives designed to influence travel behaviour towards more benign and efficient options, through marketing, information and incentives, as opposed to measures that impacted on cost of travel or implemented technology-based solutions. Examples include work and school travel plans, improved public transport information, car clubs, car sharing and teleworking. The review concluded that national traffic levels could be reduced by $11 \%$, and by $21 \%$ for peak urban traffic within 10 years, and that many such measures were cost-effective. Goodwin [12] highlights the potential for demand reduction based on the analysis of own price elasticities, stating that such effects may be limited in the short run but greater in the longer run, due to change in habits or changes in lifestyles; this is shown in Goodwin et al. [13]. Anable et al. [14] demonstrate the large impact that demand side measures can have using lifestyle scenarios that include both mode switching and demand reduction measures.

Moving passengers to non-car transport modes in urban can also be a cost-effective means of reducing congestion, pollution and reducing carbon emissions. Mass transit systems in many urban centres have demonstrated such benefits, although do face challenges of large upfront capital and require strong political will over a long time period during planning and construction [15]. 
The lack of or simplified representation of demand side measures and behavioural change in many low carbon transitions pathways reflects both the 'supply side orientation' of the modelling tools used, and consequently there is lack of information to determine the extent to which such measures can contribute, or the extent to which behaviour and demand respond under different pathways [14][16].

Building on methods developed by Daly et al. [17], the paper describes how modal shift can be incorporated into a bottom-up energy systems model. It further develops the approach by applying it to a national systems model for the UK, focusing on urban transport, incorporating non-motorised modes and characterising infrastructure capacity and costs explicitly. The latter three issues are highlighted in Schäfer [3] as particularly important elements of transport sector behaviour to represent in E3-type models.

This paper first considers key aspects of modelling transport demand in energy models in section 2 . Section 3 introduces the ESME modelling framework used in the analysis, and describes the data assumptions and approach to implement modal shift. Section 4 presents the results of the analysis, and a discussion of the key insights and requirements for further research. Finally, section 5 draws out the main conclusions from the paper.

\section{Transport sector and energy systems models}

In this section of the paper, the modelling of the transport sector in energy system models is described, including how behavioural and demand side dynamics are included. The evidence concerning the key factors in determining choices to urban travel modes is also reviewed. Finally, the issue of time budgets, and the implications of this concept to modal shift, is considered.

\subsection{Modelling transport behaviour in energy models}

Schäfer [3] suggested that the following specifications in E3 (Energy/Economy/Environment) models would be beneficial for assessing the impact of policies on behaviour change in transport. These include i) elastic transportation demand, ii) endogenous mode choice, iii) choice of no physical travel, iv) accounting for infrastructure capacity, and v) segmenting urban and intercity transport. 
Bottom-up energy system models, particularly those with optimisation frameworks, are typically limited in representing any of these features, with the exception of elastic transportation demand, and some segmenting of urban demand [18]. The baseline demands of individual modes are fixed, typically based on projections from transport sector forecasting models, so there inter-modal dynamics are not featured. ${ }^{4}$ Infrastructure costs are rarely incorporated while demand side choices that lower energy service demand, such as smarter choices or changing living patterns, are typically not considered. These models, such as those using the MARKAL/TIMES model generator, have strengths in terms of assessment of technology performance and costs. The question is how to improve the realism and extend the power of insight from these models by further incorporating behavioural features, as proposed by other researchers [19].

Other energy models, particularly those with a hybrid framework which combine both macro-economic representation and technology detail, have arguably made more progress in implementing features to model transport behaviour. For example, the Canadian Integrated Modelling System (CIMS) integrates a discrete choice model for travel and vehicle choice, based on a multinomial logit model formulation. With an integrated choice model, different policies can be assessed (e.g. carbon taxes, vehicle-type disincentives, and occupancy measures) to explore technological change [20]. Another hybrid model, IMACLIM-R (IMPact Assessment of CLIMate policies-Recursive) incorporates travel budget constraints in its utility function. As demand increases, infrastructure investment can be made endogenously to prevent time budget impacts due to slower travel speeds arising from capacity constraints [21]. Finally, the GCAM model (Global Climate Assessment Model), using a general equilibrium framework, allows for mode choice to be determined endogenously, based on the cost of transport services (including fuel price) and wage rates [22].

\footnotetext{
${ }^{4}$ One approach to endogenising modal shift in MARKAL-type models is through the introduction of cross-price elasticities. One such example is a non-linearised elastic demand variant of MARKAL called MICRO [48], although there is no evidence of its application for analysis in the literature.
} 


\subsection{Factors influencing behavioural change in urban travel choices}

The focus of this paper is on the potential shift away from cars to other modes in UK urban areas. However, determining rates of possible future modal shift is a challenge, particularly a move away from cars to other modes. Historical trends over the last 30 years show the opposite, with increasing demand for car travel, at the expense of other modes. What this analysis envisages is that modal shift could play a role in reducing transport sector emissions, with a move towards a more sustainable transport paradigm [23]. Many factors will come into play in determining whether modal shift will be realised as an effective emissions reduction measure, including the cost and speed of modes as well as individual decisions, which are influenced by urban land use planning, infrastructure spend on large scale projects, investment in public transport and societal lifestyle factors.

At the level of the individual decision maker, a number of factors come into play. A shift in modes often results due to changes in circumstance e.g. place of employment or home, known as 'churn' [12]. Due to the mobility of the population (particularly in specific regions), this can happen frequently. Goodwin cites which indicates that over a nine-year period, over $50 \%$ of commuters change their main mode at least once. Of those who both move house and change employer during two consecutive years, $45 \%$ also change mode. This highlights, that in given circumstances, mode switching does happen relatively frequently.

Other important factors around mode choice include habit [24] and access to information [25]. Habits are not only negative but could reinforce sustainable transport behaviour. They may also be the function of a number of factors; not driven only by what is considered rational (convenience, speed, cost) but also for other reasons, including lifestyle factors [12]. Kenyon and Lyons [25] note that mode choice tends to be habitual but that information could inform mode choice, where it informs on comfort and convenience in addition to cost and duration. There is also an important role for demonstration of alternatives to influence acceptance of such alternatives [23]. The role of affective (emotional) considerations is also gaining more prominence in relation to travel choices. Mann and Abraham [26] highlight how car users often highlight the importance of autonomy, personal space and ownership / identity in their choice of mode. 
In addition to factors influencing individual choice, there are a range of location-specific factors that will also have a bearing on mode shift potential, namely land use planning, urban density and the location of housing and community facilities. The availability of and extent of different public transport systems is linked to urban planning. Local initiatives and policies targeted at different modes will also have a strong bearing on mode uptake. For example, there are measures aimed at dissuading motorised transport in urban areas e.g. London Congestion Charging Zone (CCZ), ${ }^{5}$ or at incentivising other modes e.g. the cycling initiative in the City of Portland, Oregon. ${ }^{6}$

\subsection{Travel time budgets}

A key moderator of the level and rate of mode shift may be the concept of a travel time budget (TTB), where travel choices reflect an average daily travel time, and empirically that this is observed as relatively constant (and therefore stable, as proposed by Zahavi and Ryan [27]). This concept is discussed here as it informs the modal shift approach described in the next section of this paper.

The reasons for this observed constant travel budget of around $\sim 1$ hour/day/capita is that people have a certain amount of time that they are willing (or may even want) to spend on travel, and that they will make adjustments to minimize departures from that budget in either direction [28]. As the average speed of transport has increased, the apparent constancy of the time budget has remained intact, as distance travelled has increased. This time budget constant, however, is only observed at the aggregate spatial levels or for the population as a whole. As soon as one starts disaggregating populations e.g. age, gender, income etc., travel types and different spatial areas, large differences emerge [28]. Therefore it seems that the net result of large differences across the population yield a constant budget, with higher TTBs being offset by lower TTBs. This offsetting leads some to question the very constancy of the aggregate time budget, as certain variables may change over time leading to changing TTBs [29]. Some researchers have also pointed out that the data in some countries suggests non-constancy; van Wee et al. [30] point to a slowly rising TTB in the Netherlands.

\footnotetext{
${ }^{5}$ Further information on the London CCZ can be found at https://www.tfl.gov.uk/modes/driving/congestion-charge ${ }^{6}$ Portland Bicycle Plan for 2030, https://www.portlandoregon.gov/transportation/44597. Portland is considered the most bike friendly city in the USA and has seen a rapid expansion in cycling in the past 15 years.
} 
A key question is whether in the UK, a constant time budget would lead to increasing travel speeds and distances, as observed in the historic data. If indeed car travel demand is saturating, as suggested by Metz [31], a constant TTB would require average speed to reduce. Otherwise, if demand decreases and speed remains constant, TTB would reduce. As described in the next section of this paper, TTB is used as a controlling mechanism to ensure that a broad mix of modes remain, when allowing for mode shift.

\section{Methodology}

In this section, the general modelling platform used for the analysis is briefly described, followed by a description of how modal shift options are implemented in the model, for urban passenger travel demand. The underlying data assumptions which underpin this implementation are then presented, including urban transport demands, modal shift potential, time budgets and infrastructure costs.

\subsection{ESME overview}

ESME (Energy Systems Modelling Environment), developed by the Energy Technologies Institute (ETI), is a fully integrated energy systems model (ESM), used to inform the ETI's technology strategy about the types and levels of investment to make in low carbon technologies, to help achieve the UK's long term carbon reduction targets [32]. Built in the AIMMS environment, the model uses linear programming to assess cost-optimal technology portfolios. The mathematical programme is similar to that used in other bottom-up, optimisation models, such as MARKAL-TIMES [33], where the objective function is to maximise total economic surplus, subject to predefined technology capacity and activity constraints, as well as policy constraints (e.g. Renewable Energy target). The total economic surplus is calculated as the sum of the discounted system wide costs, including the change in consumer surplus and costs associated with technology investment and operation, and resource commodities.

Transport projected demands are exogenous inputs to the model, and specified for individual modes, based on forecasts from government analysis, including the National Transport Model [34]. Regional projections are further estimated, based on a range of regional datasets, including population statistics. In ESME, each mode demand is separately satisfied in a given period, net of any price-induced demand response. 


\subsection{Model implementation of modal shift}

Endogenising a shift between transport modes is a significant challenge in bottom-up, optimisation models (as discussed in the earlier section of this paper). Daly et al. [17] first introduced an approach to achieve this; instead of specifying individual travel demands, a single passenger travel demand is introduced, and different modes compete to meet this demand based on their costs (technology, fuel and infrastructure) and associated travel time. The optimisation is subject to an aggregate travel time balance, and the model is allowed to invest in infrastructure which reduces the travel time associated with different modes. Hence, with a high marginal cost of $\mathrm{CO}_{2}$, the model invests in infrastructure which enables a mode-shift away from private cars.

The approach in this paper builds from that developed by Daly et al. [17]. This includes introducing two new constraints to better represent the dynamics of mode shift: firstly, the maximum modal shift potential from cars to non-car modes, and secondly, the rate of modal shift. In addition, the option for non-motorised modes is introduced, with some representation of mode infrastructure. An important distinction, however, is that infrastructure investment does not lead to improvements in travel time associated with different modes.

The focus of this modal shift analysis is urban passenger travel demand for trips less than $55 \mathrm{~km}$ in distance. Further information on how urban travel demands are estimated can be found in section 3.3. Longer distance $(>55 \mathrm{~km})$ urban demand and all rural surface transport demands are modelled as per the standard version of ESME, using fixed mode-specific travel demands.

The objective function of the model is to calculate the optimal configuration of the energy system according to minimum costs, subject to constraints, as described for the ESME model in Section 3.1. However, instead of specifying individual travel demands for different passenger modes, $m$, this approach specifies a single passenger urban demand, $D^{u r b}$, and allows the optimal configuration of travel demand in each mode, $T_{m}$, to meet that demand:

$\sum_{m} T_{m}^{u r b} \geq D^{u r b}$ 
However, the mix of modes to satisfy $D^{u r b}$ is subject to a time resource constraint, modelled via a travel time budget, TTB. The travel time budget TTB for a region $i$ is calculated as:

$T T B_{i}^{u r b}=\operatorname{pop}_{i} \times t t b \times A F$

where $\operatorname{pop}_{i}$ is the population of the urban region, $t t b$ is the daily personal travel time budget of 0.95 hours per person per day, and $A F$ is the adjustment factor allowing for a slower mix of modes in the future.

Given $T T B^{u r b}$, the average speed of the mix of modes must be sufficient to remain within the travel time budget. Therefore, travel demand shares by different modes, $T_{m}$ in passenger kilometres per year, are such that, given the speed of those modes, $s_{m}$ in kilometres per hour, the travel time budget is not exceeded:

$\sum_{m} T_{m} \div s_{m} \leq T T B^{u r b}$

The model must utilize existing or build new transport infrastructure for each travel mode to represent the requirements for growth of new modes. Infrastructure is represented as a proxy. Only activity for each mode above 2010 activity levels incurs an additional infrastructure cost, expressed in $£ / p k m$ (see section 3.4). For any given urban mode, the amount of travel demand time requirement (given the mode speed), $T T B_{m}$, must be supported by the requisite proxy existing and new infrastructure, $T T B E_{m}$ and $\operatorname{TTBN}_{m}$ :

$T T B E_{m}^{u r b}+T T B N_{m}^{u r b} \geq T T B_{m}^{u r b}$

Finally, the absolute level and rate of change for each mode share is constrained, as justified in section 3.4. The absolute level of mode share, $v_{i}$, is constrained:

$\frac{T_{i}}{\sum_{m} T_{m}} \leq v_{i}$

The annual rate of change of passenger demand in year $y, T^{y}$, is limited by rate $r$ for each mode:

$\Delta T_{m}^{y} \leq r_{m}$

A schematic representation of the modal shift implementation in ESME, as described above, is provided in Figure 2. 
Figure 2. Implementation of modal shift in ESME

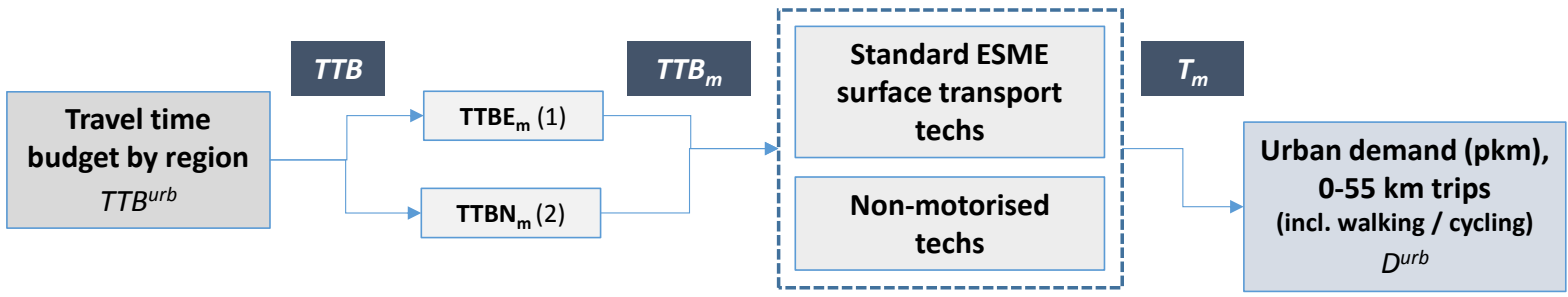

(1) Proxy tech. for current mode activity levels. No direct costs associated. Tech. controls for mode speed (ratio of TTB:TTB $\left.{ }_{m}\right)$.

(2) Proxy tech. for demand growth out to 2050, including growth under ESME projections and endogenous modal shift. Controls for level and rate of shift, infrastructure costs, and mode speed.

\subsection{Urban passenger transport projections}

Allowing for competition between urban modes means the use of a single non-mode-specific travel demand, $D^{u r b}$, expressed as passenger-km (Equation 1). The demand projection has been estimated primarily using NTS data; from the 2010 dataset, per capita travel demand by mode has been determined for two trip types - i) urban household trips of $<55 \mathrm{~km}$, and ii) urban household trips of $>55 \mathrm{~km} \&$ all rural household trips [35]. ${ }^{7}$

Due to significant differences in trip profile, London households have been differentiated from all other regions. Per capita mileage values are shown in Figure 3, as is the travel time per capita, an important metric in determining travel time budgets and mode speed (as discussed later). Per capita mileage is dominated by car travel, accounting for $87 \%$ of 'Urban $>55 \mathrm{~km} \&$ rural' and $78 \%$ of 'Urban $<55 \mathrm{~km}$ '. For Greater London, the car share for 'Urban $<55 \mathrm{~km}$ ' is much lower, at $49 \%$.

These per capita values have been scaled, using population estimates from the Rural/Urban Local Authority Classification $[36],{ }^{8}$ to determine total mileage by region by mode. The resulting $\%$ shares by mode between 'urban $<55 \mathrm{~km}$ ' and 'urban $>55 \mathrm{~km} \&$ rural' travel demands is then applied to the ESME travel demands. Walking and cycling demands, not in the current version of ESME, are based on the actual scaled estimates.

\footnotetext{
7 National Travel Survey, 2002-2012 [computer file]. 7th Edition. Department for Transport. Colchester, Essex: UK Data Archive [distributor], April 2012. SN: 5340.

http://discover.ukdataservice.ac.uk/?q=national+travel+survey\&sf=Data+Catalogue\%7CSeries\&searchType=data\#5340

${ }^{8}$ Dataset of population for England LAs can be found at

http://archive.defra.gov.uk/evidence/statistics/rural/documents/rural-defn/LAClassification-dataset-post0409.xls.
} 
Figure 3. Per capita rural and urban mileage (left) and trips (right) by mode, 2010
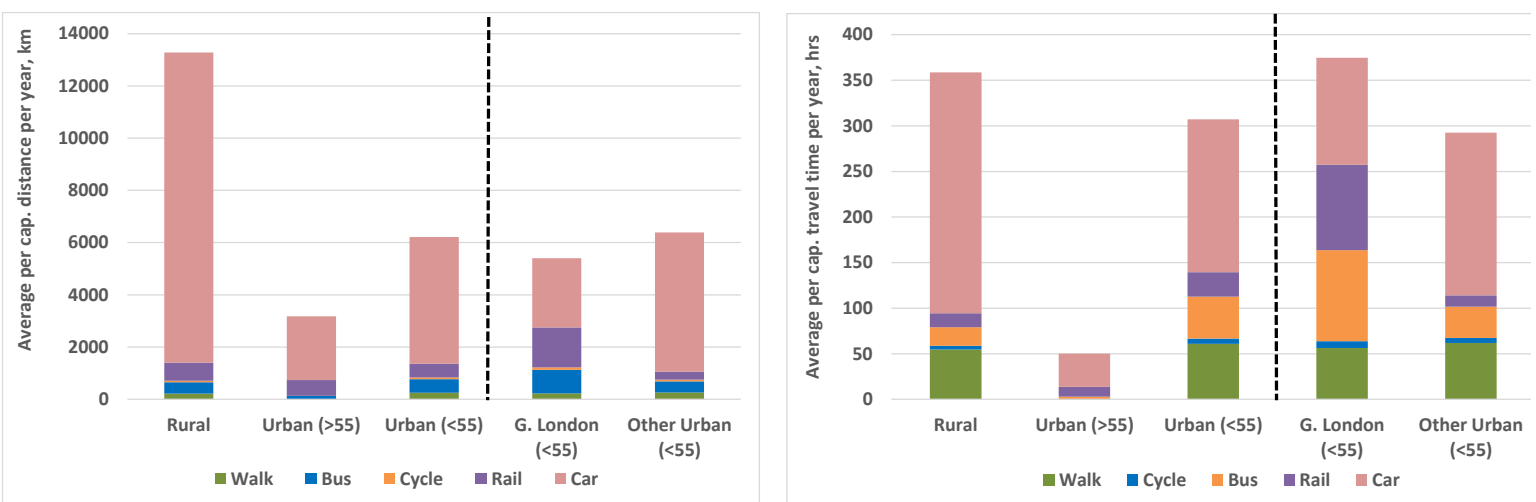

NB. Distance criteria of $<55 \mathrm{~km}$ used in analysis, and differentiated between Greater London and all other urban areas.

A final step is to aggregate the 'urban $<55 \mathrm{~km}$ ' demands by mode into a single urban demand, $D^{u r b}$, for each region. The 'urban $>55 \mathrm{~km} \&$ rural' travel demands are included in the model as mode-based demands, and not subject to modal shift. The resulting 'urban $<55 \mathrm{~km}$ ' demand is approximately $42 \%$ of total surface transport passenger demand.

The demands are projected based on the ESME demand projections. For the purpose of simplicity, it is assumed that the relative split between urban and rural demands remains the same over time. For walking and cycling, provided only for the 'urban $<55 \mathrm{~km}$ ' demand, these are projected based on estimates of future population.

\subsection{Modal shift potential}

There are three sets of assumptions that impact on modal shift in the model, including i) maximum level and rate of modal shift; ii) speed of modes, given the population's time budget requirement, and iii) costs of different modes. In this section, we explore each in turn, describing the assumptions used in the modelling.

\section{Maximum level and rate of modal shift}

Determining rates of possible future modal shift is a challenge, for the range of reasons described earlier. An initial limit of the maximum car share replacement by any single mode is based on the trip distance profiles, using 2010 National Travel Survey data. These profiles, shown in Figure 4, determine what proportion of trips of a given distance can typically be met by different modes. For example, walking 
can only meet very short distance trips, and therefore its potential capture of car demand share (in distance terms) is limited.

Figure 4. Trip distance profiles for Greater London (left) and other urban regions (right), 2010
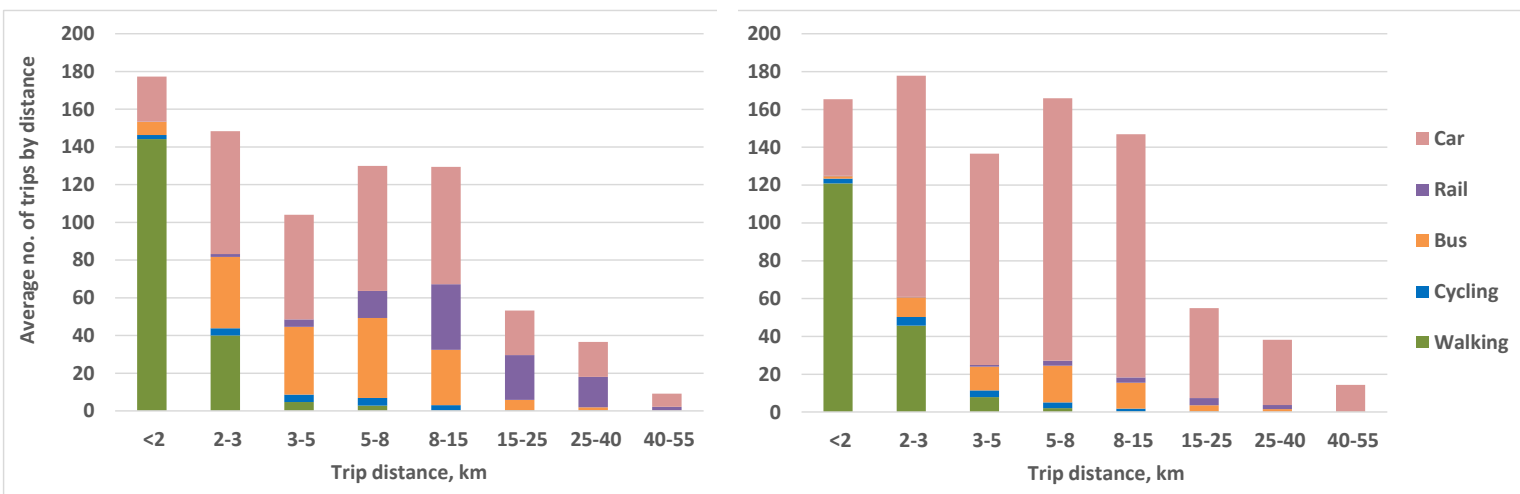

Building on the limits using the trip distance profiles, further consideration is given to other factors to set a maximum per capita demand by mode that could be achieved by 2050 (Equation 5). The estimates, in Table 1, are informed by specific analyses and international experiences. Per capita demand levels tend to be higher in London by 2050 , due to higher existing levels of non-car modes and a more extensive public transport infrastructure. While Table 1 shows increases across modes, for cars it reflects the illustrative shift away based on maximum per capita levels being met across all other modes.

Cycling limits have been considered in most detail given the data availability. By 2050, per capita levels increase by $700 \%$; this is in line with the Mayor's current ambition, to increase cycling trips by $400 \%$ by $2026,{ }^{9}$ and is also reflective of other analysis of cycling potential in London [37]. Per capita $\mathrm{km}$ increases from $89 \mathrm{~km}$ to $670 \mathrm{~km}$ by 2050 , still below the current Dutch average of $850 \mathrm{~km}$ per year. ${ }^{10} \mathrm{~A}$ strong average increase, albeit lower than for London, is assumed for other regions, to $400 \mathrm{~km}$ per capita by 2050 . Further research is needed to enhance our understanding of the share that bus and rail travel could capture by 2050 .

\footnotetext{
${ }^{9}$ London's cycling revolution, see https://www.london.gov.uk/priorities/transport/cycling-revolution

${ }^{10}$ Ministerie van Verkeer en Waterstaat report, Cycling in the Netherlands, http://www.fietsberaad.nl/library/repository/bestanden/CyclingintheNetherlands2009.pdf
} 
Table 1. Maximum levels of per capita demand by mode in 2050

\begin{tabular}{|l|ll|ll|}
\hline Mode & Greater London & \multicolumn{2}{c|}{ Urban (exc. London) } \\
\hline & $\begin{array}{l}\text { Max \% increase } \\
\text { in trips by 2050 }\end{array}$ & $\begin{array}{l}\text { Max per cap. km } \\
\text { demand (current level) }\end{array}$ & $\begin{array}{l}\text { Max \% increase } \\
\text { in trips by 2050 }\end{array}$ & $\begin{array}{l}\text { Max per cap. km } \\
\text { demand (current level) }\end{array}$ \\
\hline Cycling & $700 \%$ & $670(89)$ & $580 \%$ & $400(66)$ \\
\hline Bus & $25 \%$ & $1130(906)$ & $125 \%$ & $964(430)$ \\
\hline Rail & $23 \%$ & $1875(1526)$ & $91 \%$ & $616(313)$ \\
\hline Walking & $12 \%$ & $220(192)$ & $25 \%$ & $246(199)$ \\
\hline Car & $-64 \%$ & $1470(2649) ;-44 \%$ in & $-34 \%$ & $4106(5318) ;-23 \%$ in \\
& & km travelled & & km travelled \\
\hline
\end{tabular}

The maximum shares of the different modes by mileage and trip for Greater London and the other urban regions are shown in Figure 5. The pre-shift shares are illustrative of the situation today while the postshift shares reflect all non-car modes at their maximum potential (on a per capita basis), with any increase reducing the share of the car mode.

Figure 5. Illustrative per capita distance and trip shares by mode, before shift and after maximum shift levels for Greater London left) and other urban regions (right)
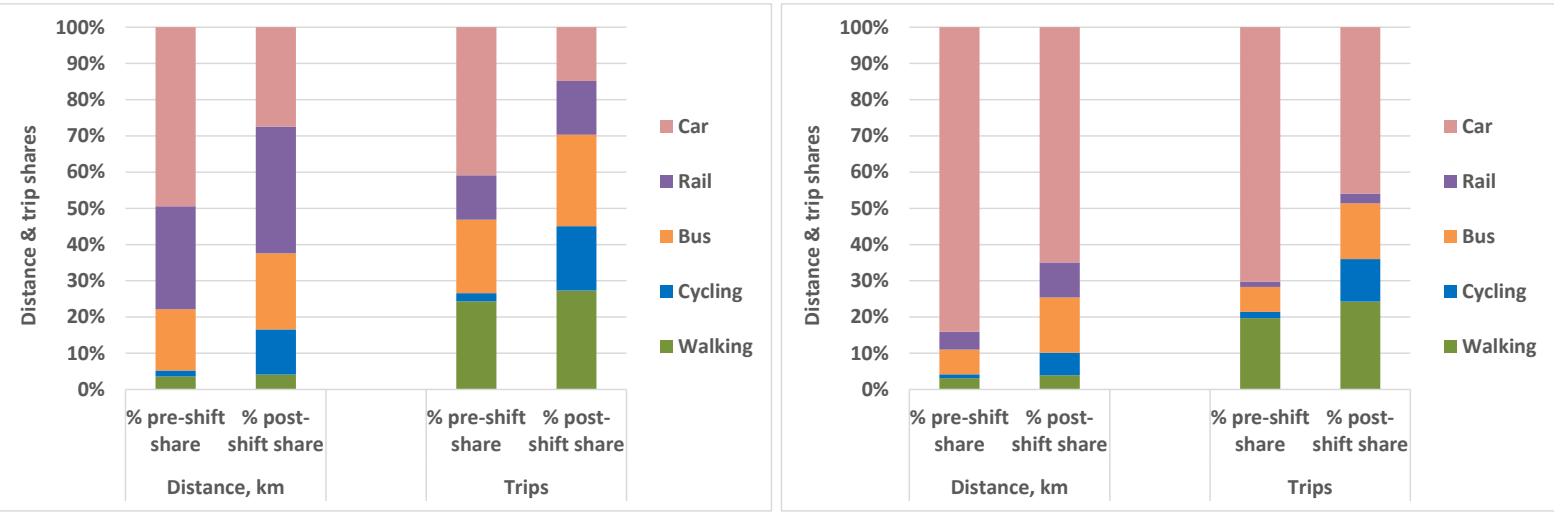

The rate of modal shift is based on a linear interpolation between the current level and maximum level in 2050. The implementation approach can be further elaborated using the example of rail provided in Figure 6.

The current level of rail demand in 2010 is around 15 bpkm per year; demand projections used in ESME suggest this could rise to just over $30 \mathrm{bpkm}$ by 2050, shown by the red trend line. The potential additional growth due to modal shift is shown by the shaded area. It is estimated that by 2050 the maximum displacement of other modes could be $40 \mathrm{bpkm}$ above the ESME projected level. Any growth 
in demand above the 2010 demand level is subject to additional infrastructure costs, and controlled in the model implementation by the $\mathrm{TTBN}_{\mathrm{m}}$ technologies (see Error! Reference source not found.). Such an approach is taken for all non-car modes. For car modes, only the ESME projected level is permitted, with no potential for additional growth via modal shift.

Figure 6. Potential rate of modal shift for rail, 2010 - 2050

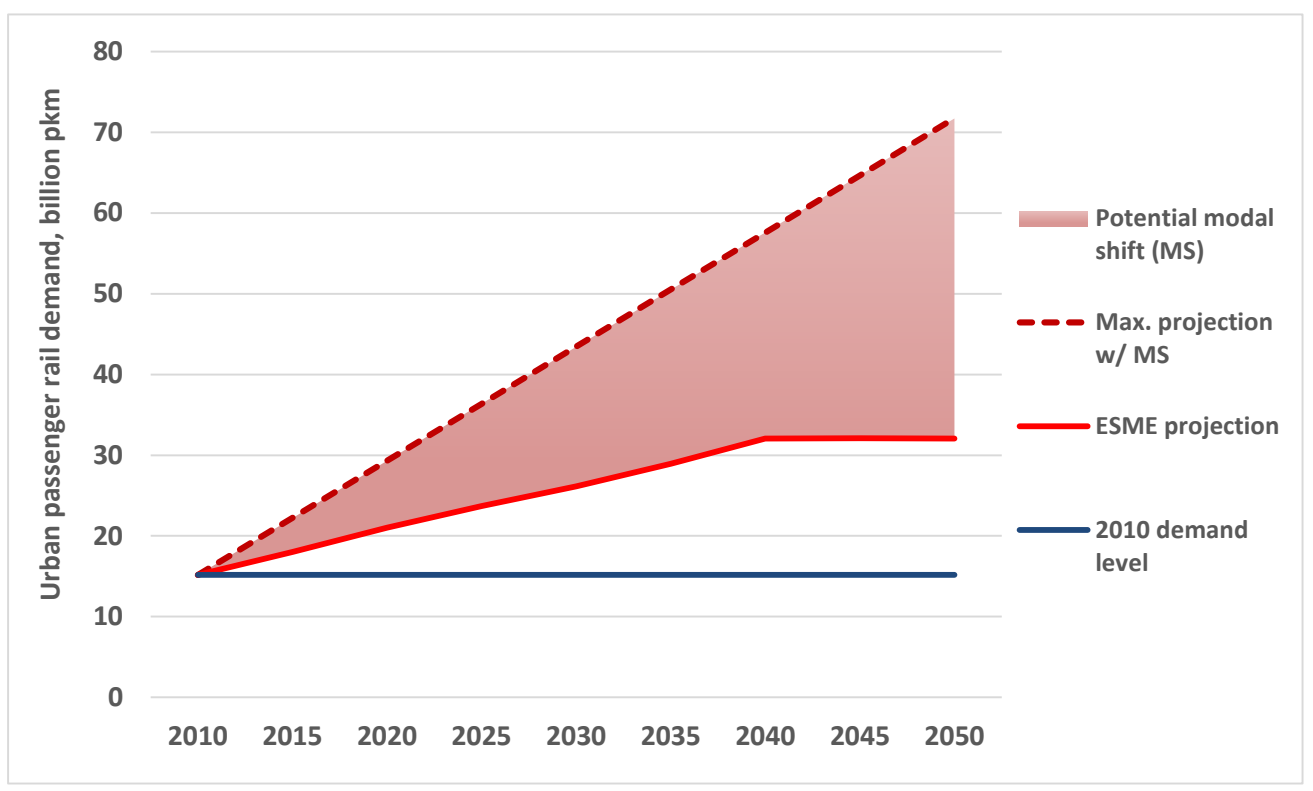

Two points are worth highlighting; firstly, all modes can potentially compete with each other for travel demand; for example, non-car modes can displace cars but also other non-car modes. Cars are treated differently, in that they cannot displace other modes i.e. car demand cannot increase above the projected level in the standard ESME projection). Secondly, it is likely that most modes will at least retain their 2010 capacity levels, as this is existing infrastructure, with no additional costs incurred. However, depending on the stringency of other constraints e.g. $\mathrm{CO}_{2}$ or time budgets, it is possible for the model to displace a given mode below its 2010 level.

\section{Mode speed and time budgets}

The use and implementation of time budgets, described in section 3.2, makes use of an adjustment factor, $A F$, in estimating the aggregate time budget. Its role is illustrated in Figure 7. If population (green line) and urban travel demand (blue line) is plotted over time, stronger growth in travel demand is apparent, due to an assumed growth in per capita demand, particularly for cars (although this continued growth is contested by some; see [31] for the arguments). If a constant TTB is assumed over time based 
on the current average of 57 minutes per capita per day, average urban speeds will have to increase (red discontinuous line). However, urban modes competing with cars tend to be slower. Therefore, as Bannister [23] states there is a contradiction between the desire to speed up and the desire to slow traffic down.

Figure 7. Projected population and assumed average speed based on constant and adjusted time budgets

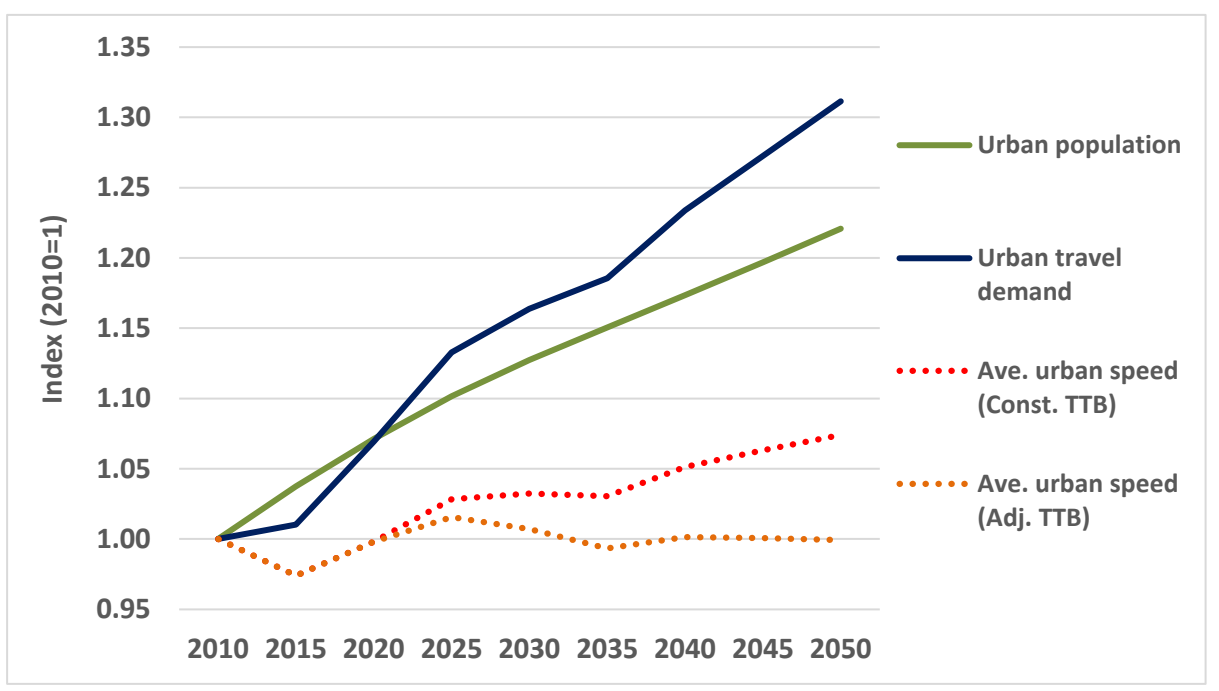

The inclusion of $A F$ allows for slower modes under the aggregate time budget, by increasing per capita budgets by $7.5 \%$, from 57 to 61 minutes. The effect, as shown by the orange discontinuous line, means that average urban speeds do not have to increase despite increasing demand. Given uncertainties in per capita travel demand increases and travel budgets in future years, this is small adjustment, and one that requires further sensitivity analysis.

\section{Mode costs}

Within the bounds provided by mode shift, time budget and other transport sector constraints, the mode choice decision is a function of cost-optimisation. This means that there is a need for comparable engineering cost estimates, which has been done by introducing an infrastructure cost component. This was particularly important for the rail mode, which is low cost in the standard version of ESME as it only captures investments associated with rolling stock but not the rail system as a whole. 


\begin{tabular}{|ll|}
\hline Mode & Sources of information for infrastructure costs \\
\hline Cycling & $\begin{array}{l}\text { The costs for cycling represent the year-on-year investment required to get to a specific level of } \\
\text { cycling trips, and therefore captures a broader set of measures than simply investment in } \\
\text { infrastructure. In the Get Britain Cycling report, it was stated that there was a consensus that around } \\
£ 10-20 \text { / capita year-on-year spend being able to deliver trip mode shares of 20-40\% [38]; The } \\
\text { London cycling strategy is funded at } £ 18 \text { / capita to deliver a 400\% increase in cycling activity by } \\
\text { 2026 [39]. These values have been converted to } £ / p k m \text { by calculating the total investment needed } \\
\text { to deliver a 20\% or 40\% mode share. A 20\% mode share costs more (on a pkm basis) due to the } \\
\text { lower pkm delivered, assuming a constant } £ 20 \text { per capita year-on-year spend. This decreases as a } \\
\text { higher share is achieved. The costs are entered into the model as decreasing over time, assuming } \\
\text { that the cycle mode share is increasing. The investment cost of bikes has not been explicitly } \\
\text { included. }\end{array}$ \\
\hline Bus & $\begin{array}{l}\text { As per car mode (below); the pkm costs are lower due to the higher passenger occupancy of buses } \\
\text { (McKinsey [40] estimates are in vkm, not pkm). }\end{array}$ \\
\hline Rail & $\begin{array}{l}\text { For rail, the costs of infrastructure investment and system operation have been added, based on the } \\
\text { DfT report Realising the potential of GB rail: final independent report of the rail value for money } \\
\text { study [41]. Projected future investment needs are informed based on the McKinsey report Keeping } \\
\text { Britain moving: the United Kingdom's transport infrastructure needs [40]. }\end{array}$ \\
\hline Walking & $\begin{array}{l}\text { No additional costs are assumed. Further research is needed to understand the costs associated with } \\
\text { enhancing urban pedestrianisation. }\end{array}$ \\
\hline Car & $\begin{array}{l}\text { Future investment needs are estimated based on McKinsey report [40]. A cost per pkm estimate } \\
\text { can be calculated based on the investment needed ( } £ 181 \text { cumulative to 2030) for a 28\% increase } \\
\text { in road demand. }\end{array}$ \\
\hline
\end{tabular}

The data sources for the infrastructure cost component of each mode are provided in Table 2. In Figure 8 , the additional cost associated with infrastructure is shown, the most significant change being the increase in costs for rail. The differences are shown between existing and new, with existing rail costs including system operation but not the capital costs of new infrastructure. Cycling is by far the most cost competitive (for those trips that can be undertaken by cycling) while bus emerges as the most costeffective motorised mode. 
Figure 8. Average costs by mode, including infrastructure costs ${ }^{11}$

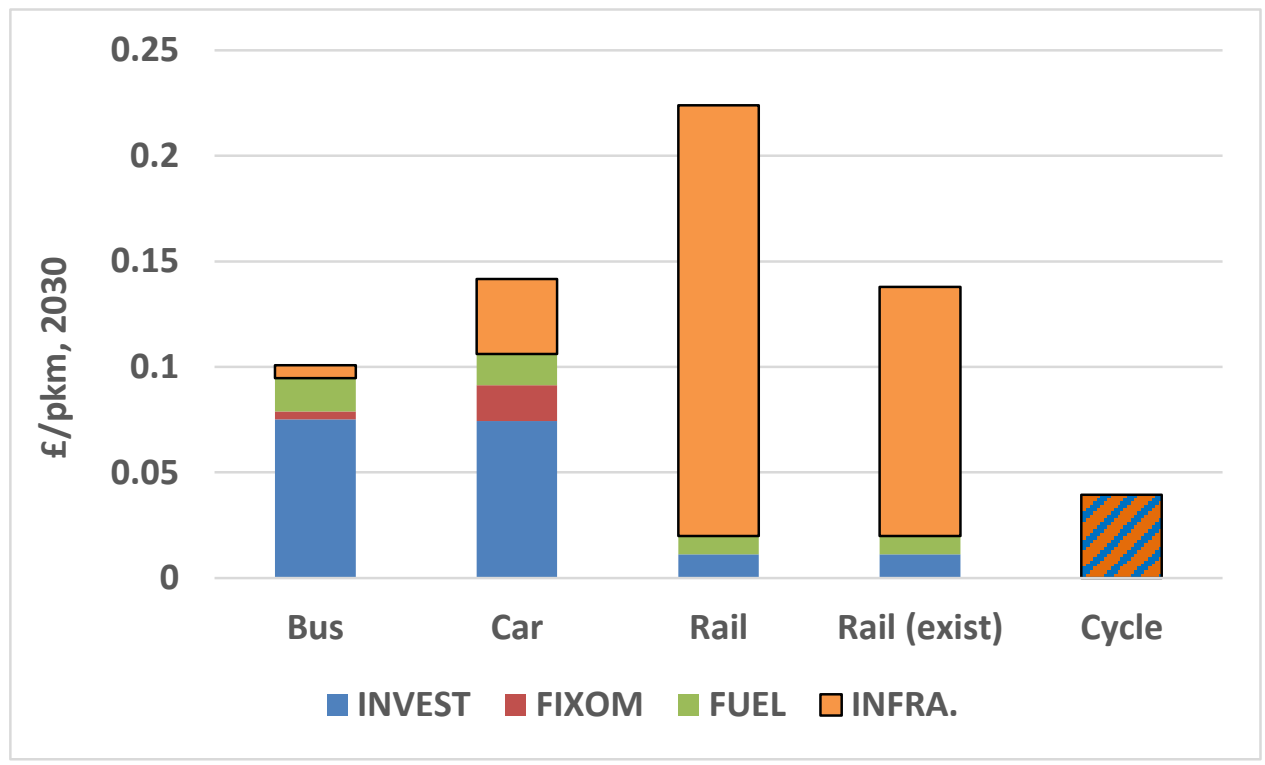

While adding infrastructure costs ensures a more comprehensive representation of technical costs, it is important to note that the modelling framework could also consider a range of other costs, although their use in the analysis would need to be carefully thought through. The first are externalities associated with mode safety, health impacts associated with active transport, and environmental impacts (noise and air pollution). The second are those that reflect behavioural decisions around transport utility, such as value of time and / or convenience / reliability.

\section{Results}

\subsection{Model scenarios}

The analysis undertaken applies the modal shift approach to ESME, quantifying the impact of endogenising modal choice to the rest of the energy system and on the resulting optimal abatement pathway of the UK energy system. All model runs use ESME v3.4 in a deterministic formulation, and include a carbon cap consistent with the UK Carbon Budget and the $2050 \mathrm{CO}_{2}$ target [1].

Beyond this reference scenario which includes mode shift (MS-Ref), four scenarios are developed to test the impact of potential future trends and policy measures on the level of mode shift and the impacts

\footnotetext{
${ }^{11}$ Cycle costs represent those necessary to increase cycling activity, and include infrastructure and investment.
} 
to the energy system. These scenarios also serve to highlight the sensitivity of the new transport demand formulation to key assumptions and inputs. Specifically, three scenarios vary individual assumptions the level of time budget applied, the maximum level of mode shift assumed, and the cost associated with private car travel assumed - and a final scenario tests the impact of varying all three, compared with the reference case. The rationale for each variation follows.

Private car costs (MS-HighCC): The core ESME assumption is that private car costs per kilometre are a function of the vehicle capital, operating costs and fuel costs (including a price for carbon), while this study has brought in the additional cost of road infrastructure. This does not take into account additional costs to society imposed by private cars, including air pollution, noise, congestion and danger, and while some of these costs are reflected in fuel duties, the full cost of these externalities are in general not reflected in the full price of private car transport [42].

In this scenario, an additional cost of $£ 0.1 / \mathrm{pkm}$ is imposed on private car transport, based on distance travelled, which can reflect a policy to incentivise other travel modes and internalise the cost associated with distance travelled, as opposed to fuel demand, which is captured in fuel taxation. External costs are very variable, depending on the vehicle type, time of travel and location/urbanity of travel, but are in general a factor of 2-5 times higher than rail travel [43]. It has been shown in energy system models before that internalising these external effects favours cleaner vehicles in transport [44], but has not been applied previously in this framework to assess the implications for optimum mode choice.

No limit on travel time budget (MS-noTTB): The mode choice approach here, developed by Daly et al. [17], is contingent on the existence of a travel time budget, described in section 2.4, which is constant over time over large populations. However, game-changing innovations to personal transport, such as driverless cars [45], and communications, such as the smartphone [46], have the potential to increase the utility associated with travel time and so cause an increase in the average TTB. The central case assumes a TTB of 61 mins per person per day by 2050, an increase from 57 mins currently, implying that urban speeds do not have to increase to satisfy the assumed growth in per-capita distance travelled. This sensitivity scenario tests the impact of TTB by removing the constraint. 
Higher potential mode shift (MS-High). As outlined in section 3.4, this model implementation relies on an assumed maximum level and rate of mode shift, with the levels used in the reference case derived from a range of studies. This sensitivity scenario assumes even greater levels of mode shift potential (+50\% on MS-Ref) across all modes (excluding walking), reflecting a world where there is great emphasis on sustainable travel, and there is a policy and behaviour push away from the private car travel.

A final scenario, $M S$-HighCC-NoTTB, is a sensitivity scenario which measures the combined impact of higher car transport costs and no time budget. The above scenarios are listed below in Table 3 .

Table 3. Model runs for modal shift analysis ${ }^{12}$

\begin{tabular}{|lllll|}
\hline Model run* & $\begin{array}{l}\text { Description, incl. purpose of } \\
\text { sensitivity }\end{array}$ & $\begin{array}{l}\text { Time budget } \\
\text { constraint included? }\end{array}$ & $\begin{array}{l}\text { Level of mode } \\
\text { shift assumed? }\end{array}$ & $\begin{array}{l}\text { Additional car } \\
\text { mode costs added? }\end{array}$ \\
\hline Ref & $\begin{array}{l}\text { ESME v3.4 standard run for } \\
\text { comparison }\end{array}$ & No & None & No \\
\hline MS-Ref & Central modal shift case & Yes & Central & No \\
\hline MS-HighCC & Higher car travel cost case & Yes & Central & Yes \\
\hline MS-NoTTB & No time budget case & No & Central & No \\
\hline MS-High & Higher modal shift case & Yes & High & No \\
\hline $\begin{array}{l}\text { MS-HighCC } \\
\text { NoTTB }\end{array}$ & $\begin{array}{l}\text { Combined sensitivity case: } \\
\text { higher car costs + no time } \\
\text { budget assumptions. }\end{array}$ & No & Central & Yes \\
\hline
\end{tabular}

\subsection{Levels of modal shift}

The first set of results, in Figure 9, shows the change in demand by mode resulting from mode shift, relative to the case where no mode shift is permitted (Ref). To provide some context for the observed shifts, a change of $20 \mathrm{bpkm}$ in 2030 is $5.2 \%$ of total shorter distance urban surface passenger demand (trips less than $55 \mathrm{~km}$ ); in 2050, 20bpkm only accounts for $4.6 \%$ of this demand due to growth in travel demand. However, in terms of the additional demand growth relative to 2010 levels, 20 bpkm represents a much larger share, at $37 \%$ in 2030 and $19 \%$ in 2050.

\footnotetext{
${ }^{12}$ All model runs include a carbon reduction trajectory consistent with the UK legislative programme of carbon budgets and $205080 \%$ target.
} 
As the rate of shift constraint is relaxed over time, modal shift increases across all sensitivities. Post2020, cycling increases at the expense of rail in all sensitivities except where the time budget constraint is removed, and car travel is penalised (MS-HighCCNoTTB, MS-NoTTB). This is not surprising, given that these are the lowest and highest cost modes respectively. The time budget constraint does moderate cycling uptake, given their average mode speed and the percentage share of trips that cycling is applicable for. This result should not be viewed, however, as cycling replacing rail travel (although this could be foreseen in some urban areas such as London); it is rather a re-adjustment of the range of trip distances covered by different modes.

Figure 9. Change in mode demand due to modal shift option, 2020-2050

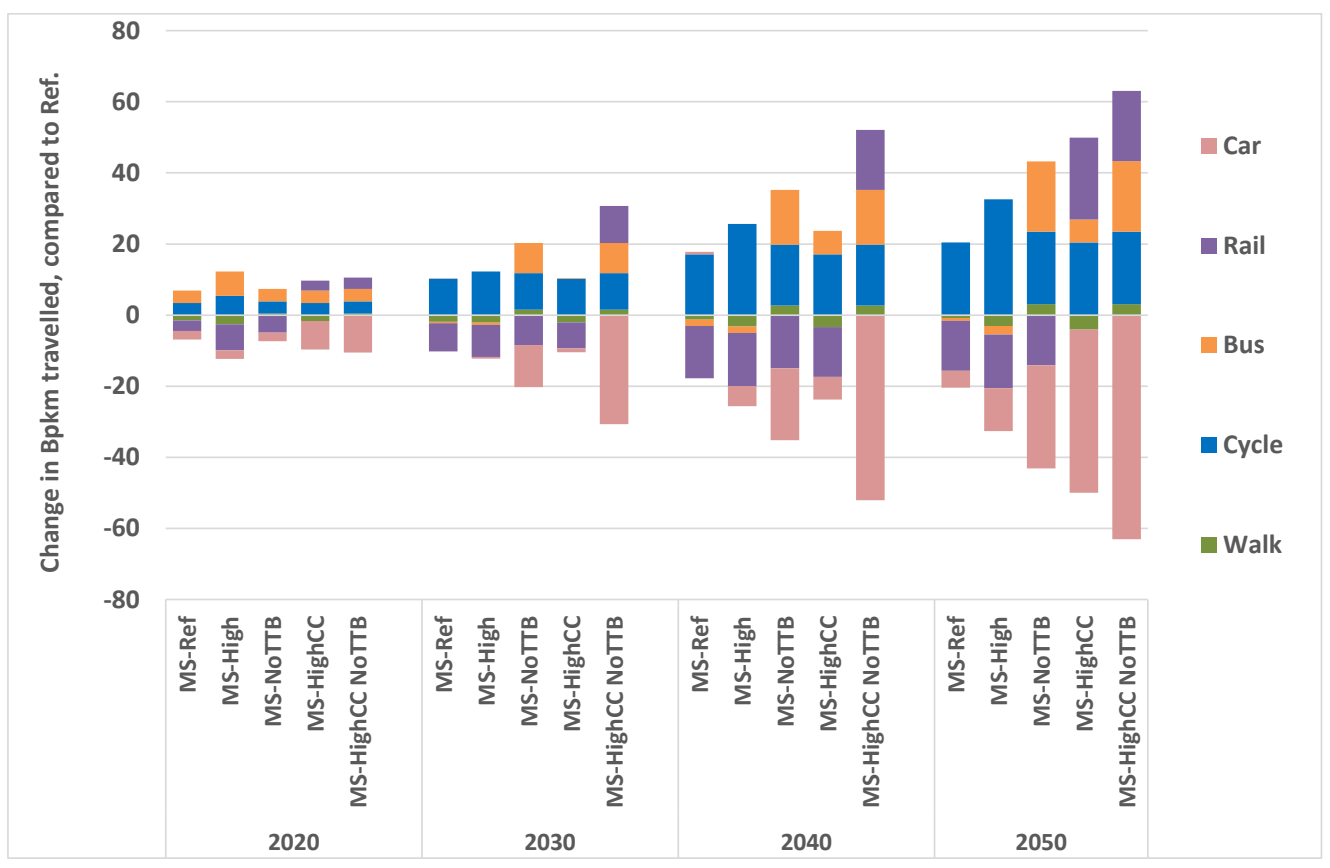

The largest shifts are observed across different modes, when either car travel is penalised with higher costs and / or travel time budgets are removed. Removing the travel time budget results in a reduction in car and increase in bus travel (MS-NoTTB), highlighting the sensitivity of bus travel to speed. The cycle share does not increase further due to limits on its share of overall travel demand. By 2050, this leads to a shift of $40 \mathrm{bpkm}$ (or $9 \%$ of total demand, $38 \%$ of demand growth relative to 2010). Compared to MS-Ref, removing the time budget constraint allows for a doubling of modal shift. Additionally increasing the costs of car travel, under MS-HighCCNoTTB, results in a three-fold increase compared 
to the MS-Ref levels. In addition to a growth in bus and cycling modes, rail now become costcompetitive, and is now a mode that grows rather than declines (relative to Ref).

An important insight from the analysis is that the cost-optimal model solution favours sustainable transport modes, although the extent of the shift is strongly contingent on financial disincentives for car travel (allowing for rail to play a stronger role) and measures to make slower modes more attractive, thereby reducing the 'need for speed' (allowing buses to play a stronger role). Cycling shifts to the maximum extent possible in all scenarios. Modes trade-off against cars as opposed to one another, except under MS-Ref, where rail demand reduces.

\subsection{Impacts on transport and wider system technology mix}

Using an integrated systems model, it is possible to explore the impact of modal shift on the technology mix, both in the transport sector and the wider system. The change in the car stock is shown in Figure 10, comparing modal shift runs to the Ref case. It highlights the shift away from ICEs in the periods 2020-2040, and then quite a significant change in the last period, with a shift away from hydrogen to PHEVs. For context, 4 million cars in 2050 is just under $10 \%$ of the total car stock.

Figure 10. Change in car stock capacity levels by type due to modal shift (top), 2020-2050, compared to reference stock levels (bottom).

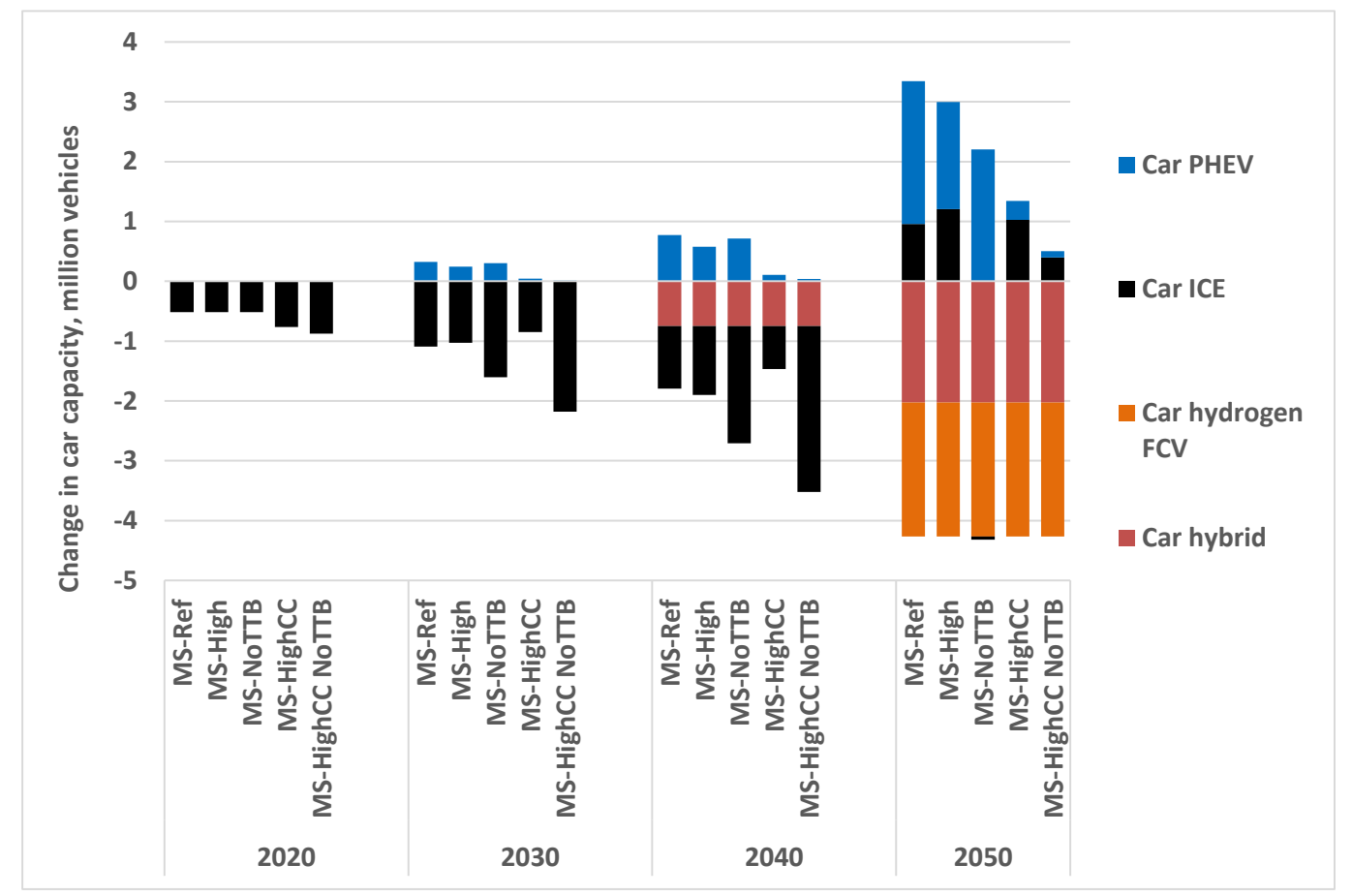




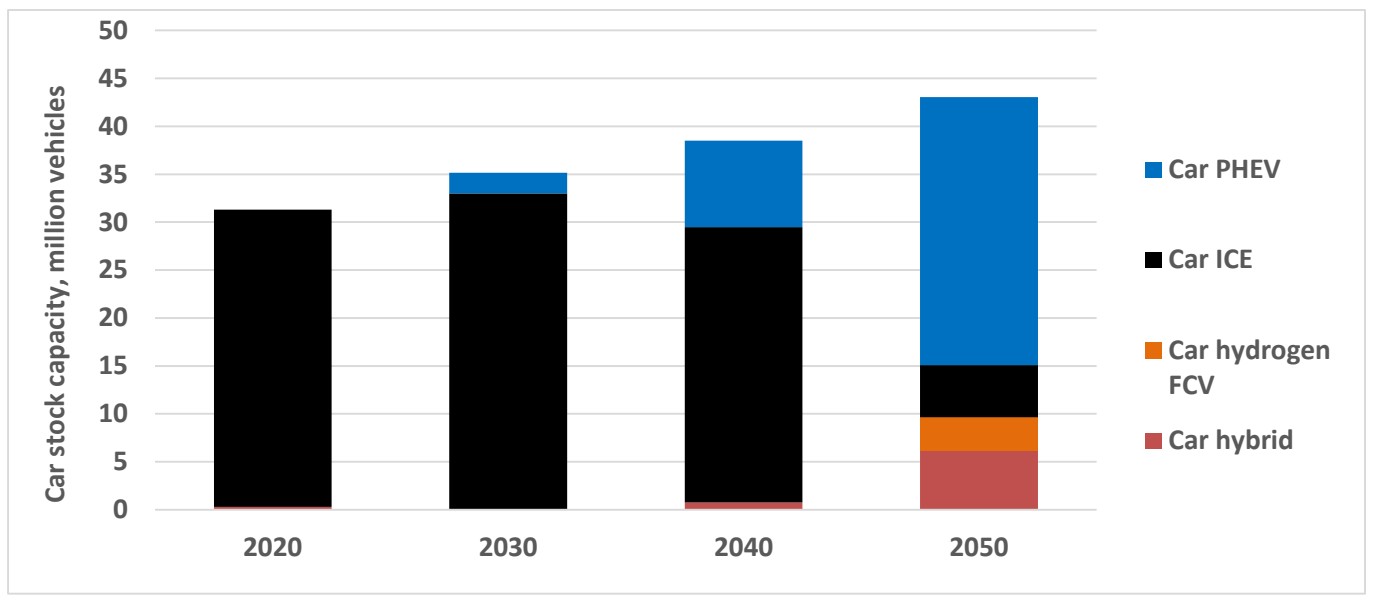

A reduction in overall car stock is expected, where the modal share of car travel reduces. To 2040, it is primarily ICE vehicles that decrease as they constitute the main share of the stock. The carbon constraint also pushes higher carbon intensity vehicles out of the mix, allowing for a more cost-effective mix of mitigation measures (as discussed later). However, the reasons for the observed changes in technology mix in 2050 are not so obvious. Hydrogen and hybrid vehicles reduce, allowing for slightly more ICEs and increased PHEVs. Modal shift measures appear to be creating 'headroom' for higher emission vehicles, and reducing the level of higher cost alternative vehicles.

This trade-off between sector emissions and mitigation costs results in lower emission reductions in this periods from the transport sector, as shown in Figure 11. This compares to increasing percentage emission reductions pre-2050, from $2-3 \%$ in 2020 to $6-9 \%$ in 2040 . However, in 2050 , the reductions are in the 3-4\% reduction range, in part due to a lower carbon transport mix in 2050 (in Ref), and the reduced deployment of higher cost hydrogen fuel cell vehicles and other higher cost measures in the wider system. Illustrative of this is the $\mathrm{CO}_{2}$ shadow price in 2050 , at a level of $£ 818 / \mathrm{tCO}_{2}$ (undiscounted) in MS-Ref compared to $£ 1044$ in the standard ESME Ref case. 
Figure 11. Change in $\mathrm{CO}_{2}$ emissions, 2020-2050

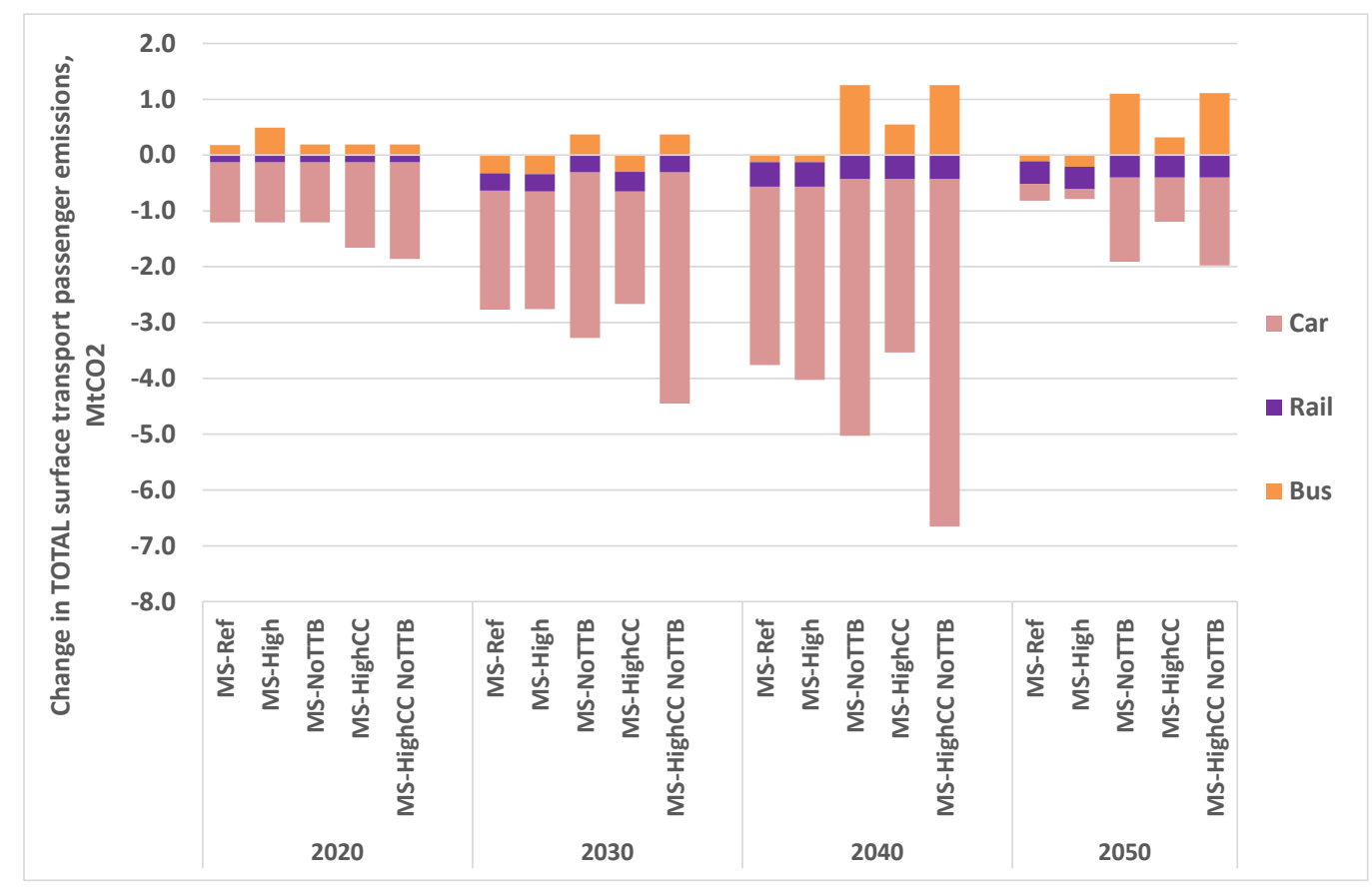

The broader impact on emissions across the energy system is shown in Figure 12. The shift in the type of emission source increases to 2040 , and then reduces in 2050 , following the pattern observed in emission reductions for passenger road transport. The reductions in emissions from transport are shaded blue. The main shift is a reduction in more expensive mitigation technologies such as IGCC biomass with CCS, and biopetrol production with CCS (shown by the green shaded column segments). There is also some reduction in the CCGT generation to 2040.

Interestingly, an increase in emission reductions from hydrogen production in 2040/2050 indicates an increase in hydrogen use ( $13 \%$ increase), despite a reduction in car hydrogen FCV uptake in 2050. The increase in hydrogen use is in the generation sector, which sees an increase in consumption of over $20 \%$ in 2050. This increased use allows a range of other generation technologies to be replaced (CCGT, IGCC biomass w/CCS). While the emission changes shown below are relatively small (at the system level), the comparison is being made with MS-Ref, the least ambitious modal shift case. System changes are much larger under those sensitivities with no time budget assumed and higher car costs. 
Figure 12. Change in $\mathrm{CO}_{2}$ emissions by source (MS-Ref compared to Ref), 2020-2050

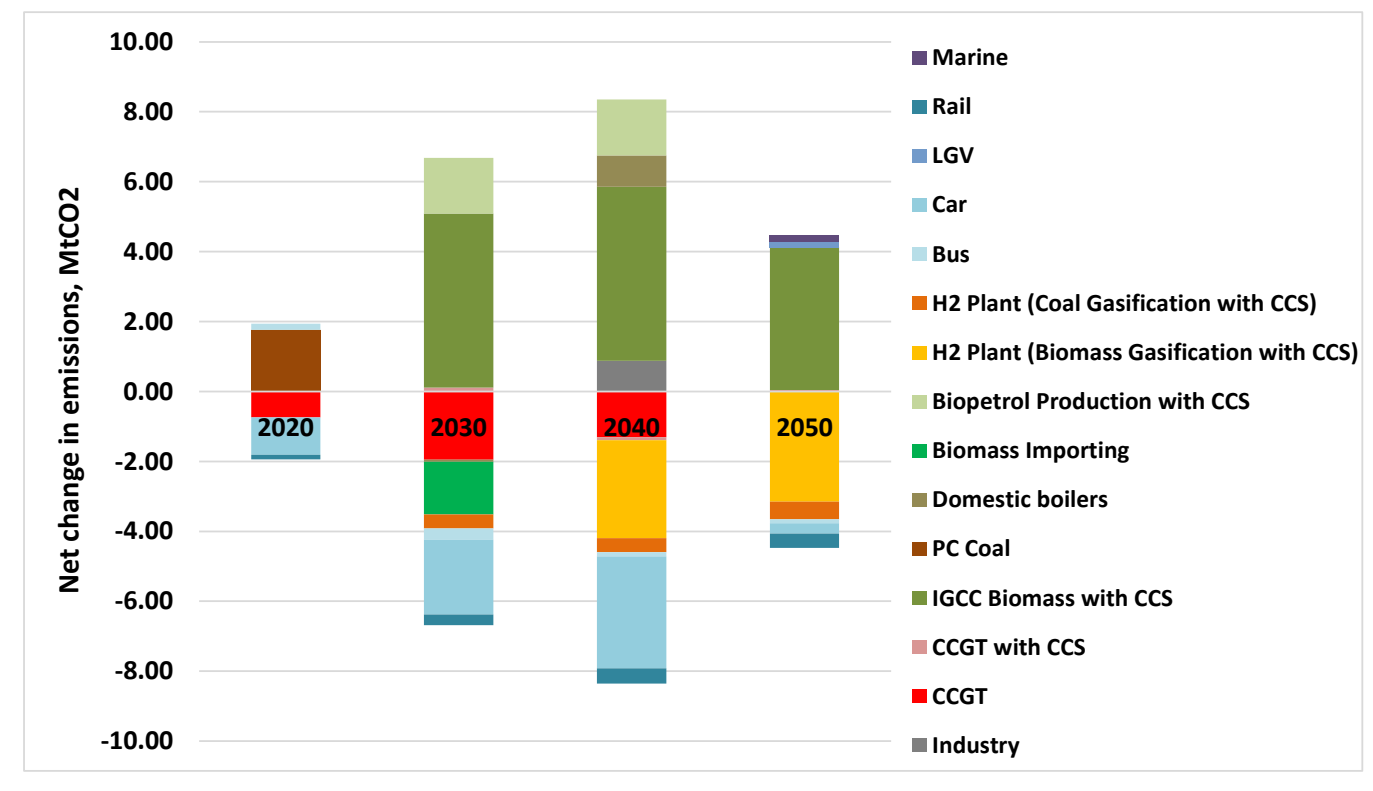

\subsection{Limitations and future work}

It is important to note that the above results are exploratory in nature, and seek to primarily demonstrate a methodology. Therefore, some refinements and further methodological considerations are necessary in determining further research. Evidently, the results are strongly influenced by some important constraints and assumptions. The scenarios outlined in section 4.2 show the particular sensitivity of the results to the level of TTB and cost of different modes. Future work should pay particular attention to the empirical basis of these parameters.

A further issue to explore is the improved representation of walking; whilst it is included in the model, it has not been sufficiently characterised and therefore has limited impact on any given solution. At the minimum, its inclusion allows for scenario analysis about the role of non-motorised modes in a future energy system, although further research is required as to the impact such modes can play [47].

There is also the issue of capacity utilisation in the model versus speed, as proposed in Waisman et al. [21]. That is greater utilisation of transport infrastructure can reduce mode speed, and that a reduction in mode speed may be mitigated by additional investment. Figure 13 illustrates the concept; existing capacity, $T T B E_{m}$, could be disaggregated to represent reduced speeds as capacity is increasingly used $\left(\mathrm{TTBE}_{\mathrm{mn}}\right)$. The model would need to choose between maintaining existing capacity (at lower speeds) or investing in new capacity $\left(\mathrm{TTBN}_{\mathrm{m}}\right)$. 
Figure 13. Introducing capacity constraint into mode shift model

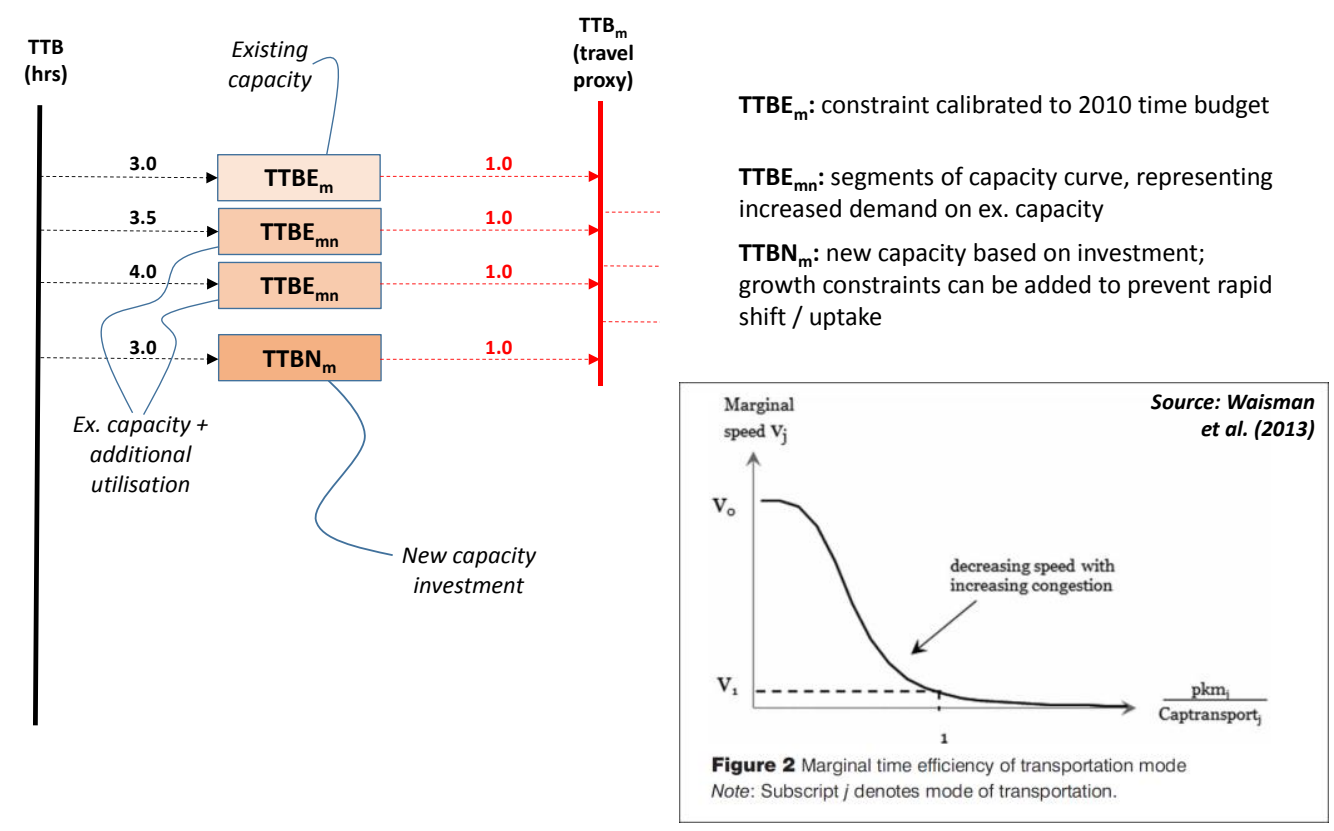

Finally, key benefits of urban mode shift away for private vehicles, namely congestion, pollution and noise alleviation, is not represented in this modelling but should be considered further. While the demand in pkm displaced is modest, mode shift displaces a much larger share of trips taken. This could have strong positive benefits for reducing congestion during peak times of the day, across different urban locations.

From a broader policy appraisal perspective, further consideration could be given to the inclusion of additional external costs, again often included in policy cost-benefit analysis. For example, it would be a relatively simple step to add in the marginal damage costs of pollution as a further decision variable between modes. This would particularly benefit non-motorised modes in urban areas.

\section{Conclusions}

In this paper, an approach to modal shift, building on that proposed by Daly et al. [17], has been described. It shows that such an approach, albeit modified, can be applied to a large systems model and produce insightful results. In addition, it makes some progress in characterising infrastructure and associated costs more explicitly, and incorporating non-motorised modes. Notwithstanding the caveats outlined in section 4.4, these results provide interesting insights, underlining the relevance of exploring the further development of this approach. 
The modelling demonstrates that around $40-60 \mathrm{bpkm}$, or $10-15 \%$ of total urban demand in 2050 , could be shifted from car travel to other modes. Such a shift has the potential to reduce emissions from urban transport, and reduce the cost of mitigation. This is done by providing 'headroom', where reductions in emissions from higher emitting transport modes allow lower cost technologies to be deployed in the wider system (Figure 12). Marginal mitigation costs drop by $20 \%$ in 2050 as a result.

Critical to higher non-car mode shares is the level of TTB; relatively small changes in the per-capita time budget allow for significantly higher levels of modal shift, and so there is a particular trade-off between moving towards a more sustainable transport and the speed of travel. A key question for policy is whether this is publically acceptable, with much dependent on the attractiveness of slower but more sustainable modes. For example, how much road space should be re-allocated to cycle lanes?

The other important sensitivity identified is that reducing car travel requires strong financial disincentives. Further sensitivity analysis is needed to establish the threshold level of disincentive at which a large modal shift is observed. The additional costs imposed in this analysis make other modes, notably rail in this analysis, much more economically attractive.

The results show that transport sector behavioural measures can have an important impact on system costs and emissions. This highlights a key deficit in many energy systems analyses, recognised by Schäfer [3]. Models that set out to provide 'optimal' solutions need to better characterise the potential for mode shift and other demand-side and behavioural measures. Otherwise, they start from a position of sub-optimality if solutions are purely supply-side driven.

\section{Acknowledgements}

The authors would like to acknowledge the funding for this work from the Energy Technologies Institute (ETI) and the input from the ETI team, led by Chris Heaton, who have provided additional information on input assumptions and further guidance on the use of ESME. 


\section{References}

[1] DECC. The Carbon Plan: Delivering our low carbon future. 2011.

[2] CCC. Fourth Carbon Budget Review - part 2: The cost-effective path to the 2050 target. 2013.

[3] Schafer A. Introducing behavioral change in transportation into energy/economy/environment models. World Bank Policy Res Work Pap 2012.

[4] Pye S, Usher W, Strachan N. The uncertain but critical role of demand reduction in meeting long-term energy decarbonisation targets. Energy Policy 2014;73:575-86.

[5] Van Wee B. The unsustainability of car use. Handb. Sustain. Travel, Springer; 2014, p. 69-83.

[6] Hickman R, Banister D. Looking over the horizon: Transport and reduced CO2 emissions in the UK by 2030. Transp Policy 2007;14:377-87.

[7] Cheng Y-H, Chang Y-H, Lu IJ. Urban transportation energy and carbon dioxide emission reduction strategies. Appl Energy 2015.

[8] Eliasson J. A cost-benefit analysis of the Stockholm congestion charging system. Transp Res Part A Policy Pract 2009;43:468-80.

[9] TfL. Central London Congestion Charging Scheme: ex-post evaluation of the quantified impacts of the original scheme. 2007.

[10] Gross, R., Heptonstall, P., Anable, J., \& Greenacre P. What policies are effective at reducing carbon emissions from surface passenger transport? A review of interventions to encourage behavioural and technological change. 2009.

[11] Cairns S, Sloman L, Newson C, Anable J, Kirkbride A, Goodwin P. Smarter choices: assessing the potential to achieve traffic reduction using "soft measures." Transp Rev 2008;28:593-618.

[12] Goodwin P. CARBON ABATEMENT IN TRANSPORT REVIEW OF DEMAND RESPONSES. Undertaken Behalf Comm Clim Chang 2007.

[13] Goodwin P, Dargay J, Hanly M. Elasticities of Road Traffic and Fuel Consumption with Respect to Price and Income: A Review. Transp Rev 2004;24:275-92.

[14] Anable J, Brand C, Tran M, Eyre N. Modelling transport energy demand: A sociotechnical approach. Energy Policy 2012;41:125-38.

[15] Assessment GE. Global Energy Assessment. Toward a Sustainable Future. 2012.

[16] Fulton L, Cazzola P, Cuenot F. IEA Mobility Model (MoMo) and its use in the ETP 2008. Energy Policy 2009;37:3758-68. 
[17] Daly HE, Ramea K, Chiodi A, Yeh S, Gargiulo M, Gallachóir BÓ. Incorporating travel behaviour and travel time into TIMES energy system models. Appl Energy 2014;135:429-39.

[18] Loulou R, Lavigne D. MARKAL model with elastic demands: application to greenhouse gas emission control. Springer; 1996.

[19] Cayla J-M, Maïzi N. Integrating household behavior and heterogeneity into the TIMES-Households model. Appl Energy 2015;139:56-67.

[20] Horne M, Jaccard M, Tiedemann K. Improving behavioral realism in hybrid energyeconomy models using discrete choice studies of personal transportation decisions. Energy Econ 2005;27:59-77.

[21] Waisman H-D, Guivarch C, Lecocq F. The transportation sector and low-carbon growth pathways: modelling urban, infrastructure, and spatial determinants of mobility. Clim Policy 2013;13:106-29.

[22] Kyle P, Kim SH. Long-term implications of alternative light-duty vehicle technologies for global greenhouse gas emissions and primary energy demands. Energy Policy 2011;39:3012-24.

[23] Banister D. The sustainable mobility paradigm. Transp Policy 2008;15:73-80. doi:10.1016/j.tranpol.2007.10.005.

[24] Schwanen T, Banister D, Anable J. Rethinking habits and their role in behaviour change: the case of low-carbon mobility. J Transp Geogr 2012;24:522-32.

[25] Kenyon S, Lyons G. The value of integrated multimodal traveller information and its potential contribution to modal change. Transp Res Part F Traffic Psychol Behav 2003;6:1-21.

[26] Mann E, Abraham C. The role of affect in UK commuters' travel mode choices: an interpretative phenomenological analysis. Br J Psychol 2006;97:155-76.

[27] Zahavi Y, Ryan JM. Stability of travel components over time. Transp Res Rec 1980.

[28] Mokhtarian PL, Chen C. TTB or not TTB, that is the question: a review and analysis of the empirical literature on travel time (and money) budgets. Transp Res Part A Policy Pract 2004;38:643-75.

[29] Goodwin PB. The usefulness of travel budgets. Transp Res Part A Gen 1981;15:97106.

[30] Van Wee B, Rietveld P, Meurs H. Is average daily travel time expenditure constant? In search of explanations for an increase in average travel time. J Transp Geogr 2006;14:109-22.

[31] Metz D. Saturation of Demand for Daily Travel. Transp Rev 2010;30:659-74. doi:10.1080/01441640903556361. 
[32] Heaton C. Modelling Low-Carbon Energy System Designs with the ETI ESME Model. 2014.

[33] Loulou R, Remme U, Kanudia A, Lehtila A, Goldstein G. Documentation for the TIMES model, Part II. 2005.

[34] DfT. Road Transport Forecasts 2011: Results from the Department for Transport's National Transport Model. London: 2012.

[35] Natcen. National Travel Survey 2013. 2014.

[36] Defra. Defra Classification of Local Authority Districts and Unitary Authorities in England: An Introductory Guide. London: 2008.

[37] TfL. Analysis of Cycling Potential: Policy Analysis Research Report. London: 2010.

[38] Goodwin P. Get Britain Cycling - Report from the Inquiry. London: 2013.

[39] GLA. The Mayor's vision for cycling in London. London: 2013.

[40] McKinsey. Keeping Britain moving: the United Kingdom's transport infrastructure needs. 2011.

[41] McNulty SR. Realising the potential of GB Rail: final independent report of the Rail Value for Money study. 2011.

[42] Santos G, Behrendt H, Maconi L, Shirvani T, Teytelboym A. Part I: Externalities and economic policies in road transport. Res Transp Econ 2010;28:2-45.

[43] Maibach M, Schreyer C, Sutter D, Van Essen HP, Boon BH, Smokers R, et al. Handbook on estimation of external costs in the transport sector. CE Delft Delft; 2007.

[44] Takeshita T. Assessing the effects of internalizing externalities on the road transport sector. Cape Town: 2012.

[45] Sgouridis S. The unrealized potential of Personal Rapid Transit. Netw Ind Q 2012;14:3-6.

[46] Townsend A. RE-PROGRAMMING MOBILITY: The Digital Transformation of Transportation in the United States. 2014.

[47] Brand C, Goodman A, Ogilvie D, consortium iConnect. Evaluating the impacts of new walking and cycling infrastructure on carbon dioxide emissions from motorized travel: A controlled longitudinal study. Appl Energy 2014;128:284-95.

[48] Loulou R, Goldstein G, Noble K. Documentation for the MARKAL Family of Models. Energy Technol Syst Anal Program 2004. 